\title{
Frequency response of transformer winding to investigate the influence of RLC
}

\author{
S. Al-Ameri ${ }^{1}$, M. F. M. Yousof ${ }^{2}$, Norhafiz Azis ${ }^{3}$, S. Avinash ${ }^{4}$, M. A. Talib ${ }^{5}$, Ali. A. Salem ${ }^{6}$ \\ ${ }^{1,2,6}$ Department of Electrical and Electronic Engineering, University Tun Hussein Onn Malaysia, Malaysia \\ ${ }^{3,4}$ Centre of Electromagnetic and Lightning Protection Research (CELP), Malaysia \\ ${ }^{3}$ Institute of Advanced Technology (ITMA), Universiti Putra Malaysia, Malaysia \\ ${ }^{5}$ TNB Research, Kajang, Selangor, Malaysia
}

\begin{tabular}{l} 
Article Info \\
\hline Article history: \\
Received Sep 27, 2018 \\
Revised Nov 26, 2018 \\
Accepted Dec 7, 2018 \\
\hline
\end{tabular}

Keywords:

FRA

Ladder network

Transformer model

\begin{abstract}
Frequency response measurements are used for power transformer winding failures detection. The variation between frequency responses indicate mechanical changes in the transformer winding. One method to investigate winding failures in transformer is to develop a reliable circuit model which can simulate the frequency response of an actual winding. The main reason to use the model is because it is expensive to create damages on an actual winding. This paper proposes n-stages circuit ladder network to simulate the response of a winding which has unique design. It presents a new technique to calculate the resistance, inductance and capacitance of the winding. Then, the relationship between the RLC parameters and the frequency response is studied. The winding chosen in this investigation is a single phase $33 \mathrm{kV}$ transformer winding. The simulated frequency response was compared with the measured response to verify the proposed model. The model can give a comprehensive understanding about the effect of RLC parameters on the frequency response.
\end{abstract}

Copyright $\left({ }_{0} 2019\right.$ Institute of Advanced Engineering and Science. All rights reserved.

\section{Corresponding Author:}

Salem Mgammal Awadh Nasser Al-Ameri, Department of Electrical and Electronic Engineering, Universiti Tun Hussein Onn Malaysia, 86400 Parit Raja, Johor, Malaysia. Email: mgammal10@gmail.com

\section{INTRODUCTION}

Power transformers are designed to provide safe, reliable delivery of electricity to the public and consumers. However, operating the transformer at very high loading condition to meet the demands can accelerate the deterioration of the unit. This is due to the increase of mechanical, electric, and thermal stresses during the operation. If the transformer insulation conditions degraded, the clamping pressure could become loose thus other failures accrued. This would reduce the ability of a transformer to withstand high current from short circuit fault. In addition, there are other failures that could occur such as mishandling the unit during transportation, earthquakes and even combustible gas explosion [1]. For his reason, it is important to conduct studies to investigate the transformer failures.

Today, the FRA has become a complementary technique in order to investigate the transformer failures. The FRA measurement typically performs at a frequency range $(50 \mathrm{~Hz}$ to $5 \mathrm{MHz})[1]$. Based on IEEE [2] standard and CIGRE [3] it is approximately in the range of $20 \mathrm{~Hz}$ to $2 \mathrm{MHz}$. The FRA test is used to detect mechanical deformation in a transformer. It is applied after some incidents that have the possibility of causing this mechanical or electrical damage to the power transformer. Physical changes in the resistance, inductance and capacitance network of the transformer windings can alter the mathematical transfer function. The transfer function behavior can detect a wide range of mechanical or electrical changes in the electrical 
circuit representation of the transformer. Besides mechanical damage. FRA is also sensitive to dielectric changes such as due to aging which is not categorized as a mechanical fault [4].

In order to investigate the effect of winding failures on FRA measurement, faults need to be applied in the actual winding. However, this is difficult and costly because of the transformer winding strength and the price of transformer. For this reason, it is more practical to perform winding failures in a transformer model represented using suitable software. It is known that transformer winding can be represented by electrical circuit with parameters of resistance, inductance, and capacitance (RLC). Therefore, it is important to be accurate in calculating winding parameters. There are various techniques used to simulate the transformer RLC model such as finite element method (FEM) and state space model. A study conducted in [5] used finite element analysis to calculate the inductance and capacitance of the winding in order to investigate the winding deformation. It was founded that FEM gives an accuracy in acceptable limits. Also, a study conducted in [6] to study a radial deformation in the winding using FEM. It was shown that FEM can provides a significant information about the changes of capacitance and inductance of the winding. The weakness in FEM is that it obtains only approximate solution. In addition, it was stated in [7] that FEM has an inherent error. On the other hand, a state space modeling was presented in [8] to simulate the actual measurement distribution transformer. It was founded that it is easy to realize the impact of various mechanical deformations on the transformer FRA signature.

In this paper, a lumped ladder network model is presented. The advantages of the model are that the physical meaning of the model parameters is easy to identify. This model can be used later to simulate various winding damages. For example, it is easy to identify the disc required to apply the fault in. In addition, it is more physical to make the changes. The novelty in this study is that the winding structure itself is entirely new thus poses new challenges that requires different approach to simulate the frequency response.

This study presents a lumped parameter equivalent circuit model which represent actual HV winding. The winding geometry was taken from an actual transformer HV winding. Then, the RLC parameters were calculated using a new method for the new winding structure. The simulated response shows an approximately similar when compared with the measured response. Then, changes in the RLC parameters are applied to investigate the effect on the response. This model can also be used to investigate the effect of number of discs on the response. Nevertheless, the main purpose of this study is to investigate the relationship between the level of fault-based on the change of winding resistance, capacitance and inductance.

\section{HIGH-FREQUENCY MODELING OF TRANSFORMERS}

Modeling the high frequency response of transformer winding has a certain degree of complexity. This is due to the arrangement of transformer winding electrical circuit. It is impossible to use a simple equivalent circuit to present the transformer winding. This is because at higher frequencies wavelength of the signals are compared with the transformer winding geometry [9].

The steps shown in Figure 1 are followed for calculating the high frequency response of transformer winding. The first step is to measure the winding geometry. The second step is to calculate the winding resistance, capacitance, self and mutual inductance using certain formulas. Then, the calculated resistance, series capacitance, self and mutual inductance are entered in MATLAB to calculate the frequency response.

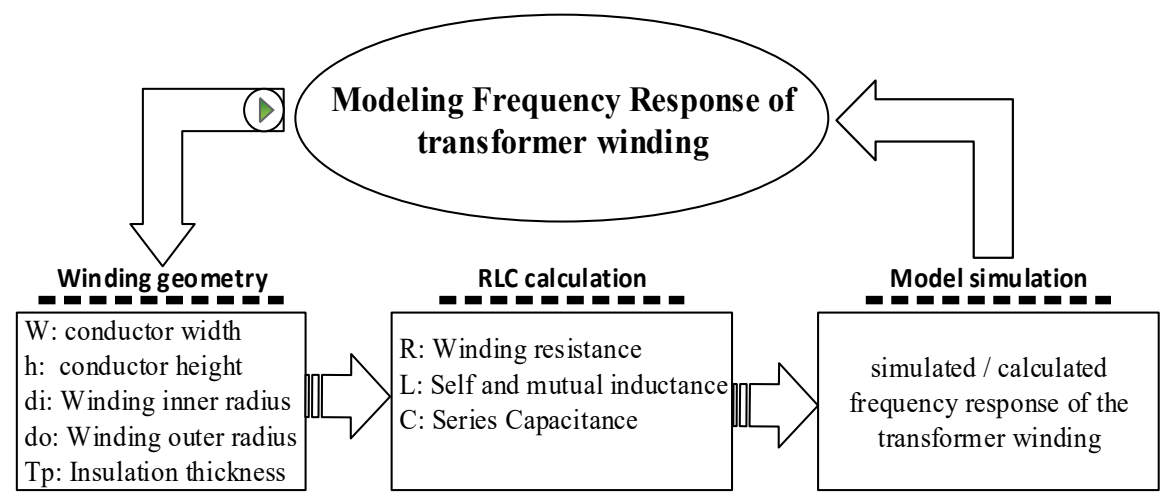

Figure 1. The modeling steps to calculate the frequency response of transformer winding

Indonesian J Elec Eng \& Comp Sci, Vol. 14, No. 1, April 2019 : 219 - 229 


\subsection{N-Ladder Network}

As shown in Figure 2 (a) n-stage of ladder network method is a well-known method to model the transformer winding. Each disc of the winding is represented by resistance, capacitance, and inductance. In every disc, for example $D 1$ shown in Figure 2(a) consists of series inductance $L s$, series capacitance $C s$, series resistance $R s$ and ground capacitance $C g$.

First step the winding geometry was measured manually such as conductor geometry and winding inner and outer radius. The transformer was approximately looked like Figure2(b). According to [10], there are several types of transformer winding and have different ways of calculation. The main types of the winding are helical winding, layer winding, and disc winding. The transformer selected in this study is disc winding.

The equivalent circuit of the disc winding transformer for n-stage ladder network is shown in Figure 2

Figure 2(a). In order to simulate the transformer winding frequency response, it is required to calculate the total series capacitance $C s$. This required to calculate the capacitance in between turns $C t$ for every disc. In the meantime, it is essential to calculate the capacitance in between discs $C d$. After that, calculate the series resistance $R s$, capacitance to the ground $C g$, conductance $G s$, self and mutual inductance $M_{L}$. Those electrical parameters must be obtained as a second step to simulate the frequency response of the transformer winding.

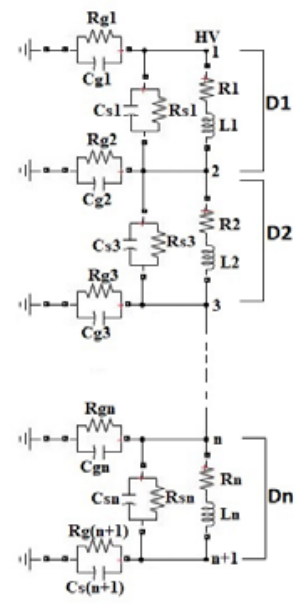

(a)

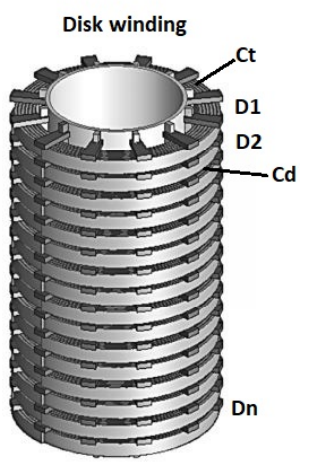

(b)

Figure 2. (a) N-stage equivalent lumped circuit for the single winding, (b) the 3D of single-phase winding [11]

\subsection{Series Capacitance Calculation}

Based on the transformer winding structure as shown in Figure 2(b), the capacitance between the conductors in the same disc $C_{t}$ needs to be calculated in order to find the series capacitance. At the same time, the capacitance between conductors in the adjacent $\operatorname{disc} C_{d}$ (capacitance between discs) is also calculated. The capacitance between two conductors represents $C_{t}$ is shown in Figure 3. The capacitance between two turns is given by (1).

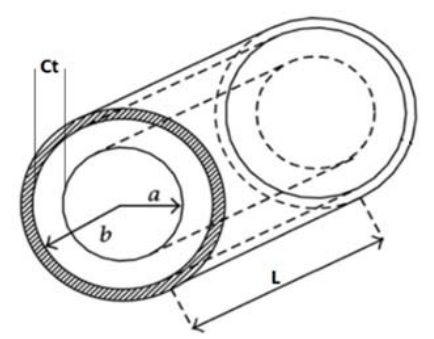

Figure 3. The two conductors diagram soiled line the first conductor doted line the second conductor [12] 


$$
C_{t}=\frac{2 \pi \varepsilon_{r} \varepsilon_{o} L}{\ln \frac{b}{a}}
$$

Where the $L$ is the length of the conductor which represent the height. $b$ and $a$ are the inner radius and outer radius of the outer and inner conductors respectively. $\varepsilon_{o}$ is permittivity of the free space which is $8.854 \times 10^{-12}$ and $\varepsilon_{r}$ is 3.85 which is the relative permittivity of the insulation paper located between the outer and inner conductors. On the other hand, the capacitance between adjacent discs as in Figure 4 can be calculated by (5) which derived as shown in (2), (3) and (4).

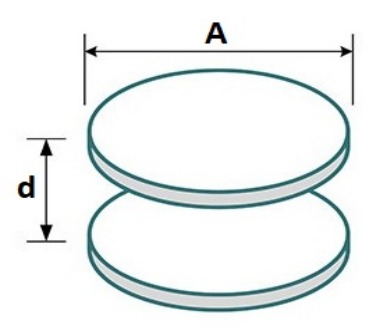

Figure 4. The capacitance in between two discs

$$
\begin{aligned}
& C_{d}=\frac{\varepsilon(A)}{d} \\
& A=\pi\left(r_{o}^{2}-r_{i}^{2}\right) \\
& A=\pi\left(\frac{d_{o}^{2}}{2}-\frac{d_{i}^{2}}{2}\right)
\end{aligned}
$$

Where: $\varepsilon=\varepsilon_{r} \varepsilon_{o}$

$$
C_{d}=\varepsilon_{r} \varepsilon_{o} \pi \times \frac{d^{\prime 2}{ }_{o}-d^{2}{ }^{2}}{4 \times d}
$$

Where: $d^{\prime}{ }_{o}=d_{o}+d$

$d^{\prime}{ }_{i}=d_{i}-d$

$d$ is the distance between turns (accounting for fringing effect). $d_{i}$ and $d_{o}$ are the inner and outer diameter if the winding. Figure 5 is an example of an equivalent network of two discs in the winding. The circuit shows that $C_{t}$ is contacted in series whereas the $C_{d}$ are in parallel. Since $C_{t}$ for every between two conductors are different due to different conductor length, therefore we calculate all $C_{t}$ and the total is considered in series as (6).

$$
C_{t \text { total }}=\frac{1}{\frac{1}{C t 1}+\frac{1}{C t 2}+\frac{1}{C t n}}
$$

On the other hand, the total capacitance between discs is given as (7).

$$
C_{d \text { total }}=C d 1+C d 2+C d n
$$

Since the capacitance in between discs is in parallel as shown in the equivalent circuit Figure 5. The total series capacitance of whole winding can be calculated as (8). However, for a one disc the total series capacitance can be obtain by $C_{d}+C_{t}$. Regarding to this particular winding in this study the in (8) can give the most similar response compared with the measured response [13], [14]. 


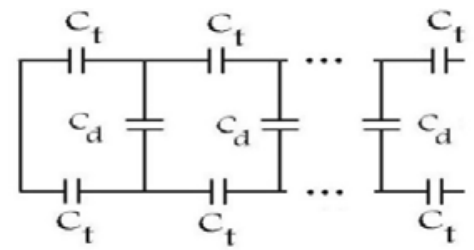

Figure 5. Layout of the equivalent capacitance diagram network of the winding

$$
\begin{aligned}
& C_{s}=\frac{1}{N d}\left(\frac{C t}{m t}+4 C_{d t}\right) \\
& C_{d t}=\frac{(m t-1)(2 m t-1)}{6 m t} C_{d}
\end{aligned}
$$

Where the $C_{d t}$ is the resultant inter-disc capacitance. In addition, there is also capacitance to the ground $C_{g}$. In this study, the measured transformer winding do not have capacitance to the ground since there is no grounded tank during the measurement. There are other electrical parameters to be calculated in order to simulate the response such series resistance $R_{s}$, self, and mutual inductance.

\subsection{The Series Resistance Calculation}

To calculate the series resistance of the winding, it is required to know the total circumference of the conductor $C_{i r}$. The total circumference is given in $C_{i r}=2 \pi r$.

$$
\begin{aligned}
& R_{s}=R_{s 1} \times C_{i r} \\
& R_{s 1}=\frac{1}{2(h+w)} \sqrt{\frac{\pi f \mu}{\sigma}} \Omega / \mathrm{m}
\end{aligned}
$$

From (10), $h, w$, are the height and width of the conductor respectively. Where $f$ is the signal frequency, $\mu$ and $\sigma$ are the permeability and conductivity of the conductor. On the other hand, the conductance $G$ is a matrix which can be obtained from (11) where $\tan \delta$ is the insulation dissipation factor.

$$
G=2 \pi f C s \tan \delta
$$

\subsection{The self and Mutual Inductance Calculation}

The self and mutual inductance between turns were obtained from (12), (13).

$$
\begin{aligned}
& L_{k m}=\mu_{o} N_{k} N_{m} \sqrt{(r \alpha)} \frac{2}{k}\left[\left(1-\frac{k^{2}}{2}\right) K(k)-E(k)\right] \\
& K=\sqrt{\frac{4 \alpha r}{z^{2}+(\alpha+r)^{2}}}
\end{aligned}
$$

Where $L_{k m}$ is the mutual inductance between disc $k$ and disc $m . r$ is the average radius of the discs and $z$ is the axial distance between the two discs. $N_{k}$ and $N_{m}$ are the number of turns in $k$-th section and $m$-th section as shown in Figure 6. $K$ and $E$ are the elliptic integrals of the first and second kinds. For selfinductance where: $k=m, z$ is calculated by $z=0.2235 \times(h+w)$. Also, $h_{1}$ and $w_{1}$ are alike to $h_{2}$ and $w_{2}$. The self inductance for the $L_{k m}$ matrix is representing the diagonal elements while off-diagonal elements are the mutual inductance between discs. In this study, the value of $r$ and $\alpha$ are equaled. This is because the average radius of the sections are the same. The value of magnetic permeability of the medium is $\mu_{0}=4 \pi \times 10^{-7}$. 


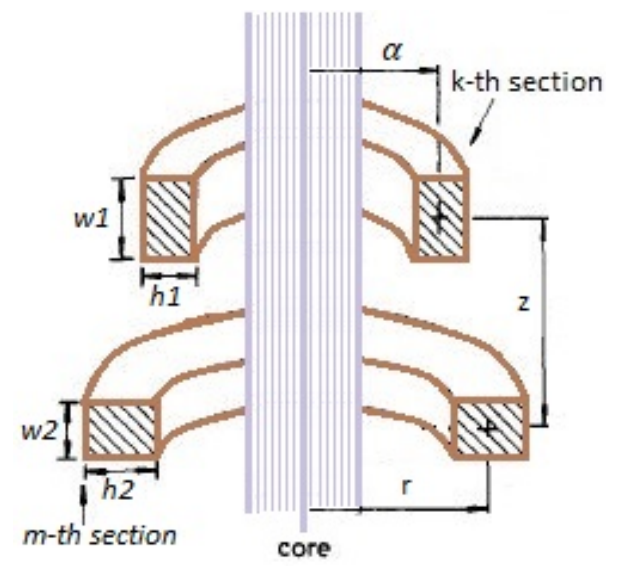

Figure 6. The general dimensions of the winding discs

\section{RESULTS AND ANALYSIS}

\subsection{Measurement of the Actual Transformer}

The measurement was conducted on an actual transformer in order to verify and compare with the developed model. FRA measurement was performed on the $\mathrm{HV}$ winding. Also, it is performed from $20 \mathrm{~Hz}$ to $2 \mathrm{MHz}$. The transfer function obtained by the ratio $V_{\text {out }} / V_{\text {in }}$ based on CIGRE reported in [3]. The measurement configuration is taken in single phase $\mathrm{HV}$ winding as shown in Figure 7 . This measurement configuration is mostly used because it provide enough information to analysis the transformer condition.

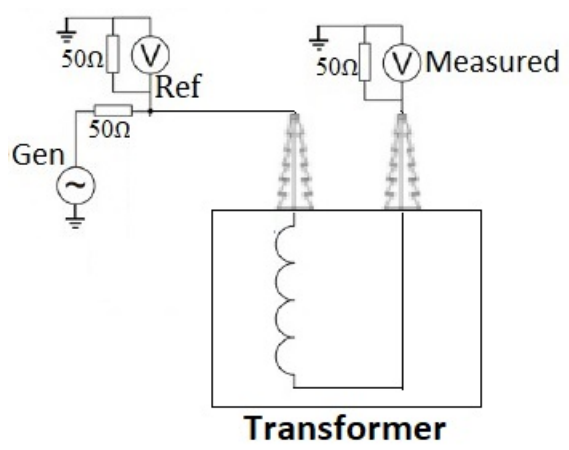

Figure 7. FRA measurement test configuration

\subsection{Parameters Calculation on the Measured Transformer}

The FRA measurement is conducted on a single phase $33 \mathrm{kV}$ HV winding. To calculate electrical parameters of the tested transformer, the specifications of the geometrical such as dimension of the conductor and thickness of the insulation are calculated. The full winding consists of 96 discs. In every disc, there are five turns. In every turns there are six conductors connected together at the terminal. This is the novelty in this paper where a new winding design is studied to calculate its electrical parameters and simulate the frequency response.

The full winding structure is shown in Figure 8 . The conductor has $2.4 \mathrm{~mm}$ width and $11.5 \mathrm{~mm}$ in height as shown in Figure 9(b). Based on Table 1 the transformer dimensions such inner and outer radius were calculated. The total circumference of the conductor is given by $2 \pi r$. The winding parameters are provided in Table 1. The insulation thickness between conductors is $0.5 \mathrm{~mm}$. However, there is an air gap between turn 3 and turn 4 . The $5 \mathrm{~mm}$ air gap is shown in Figure 9 (a). 


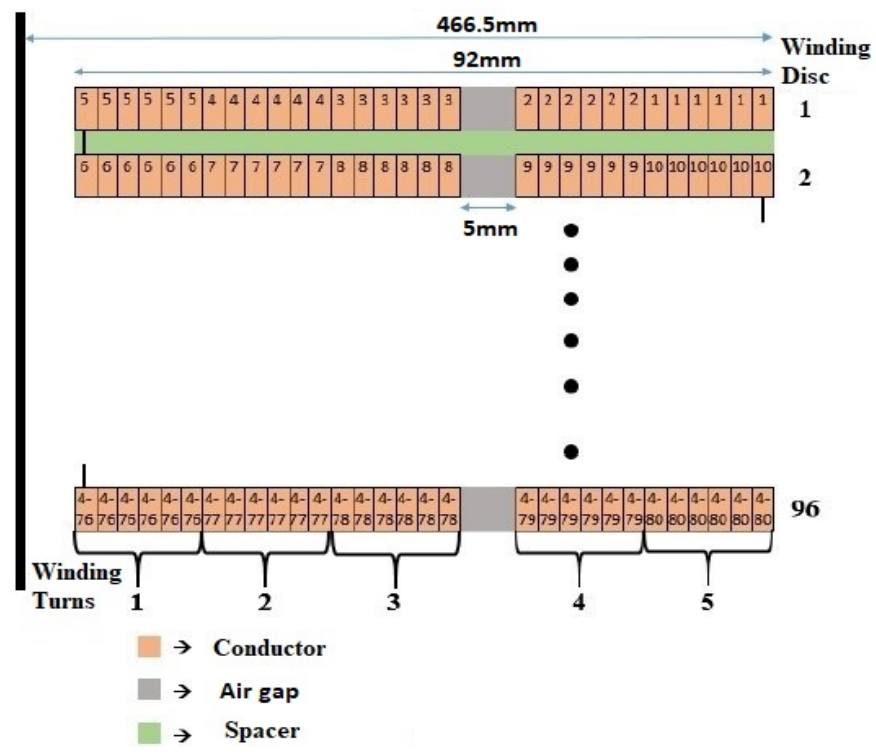

Figure 8 . The 2D for the full winding structure tested transformer

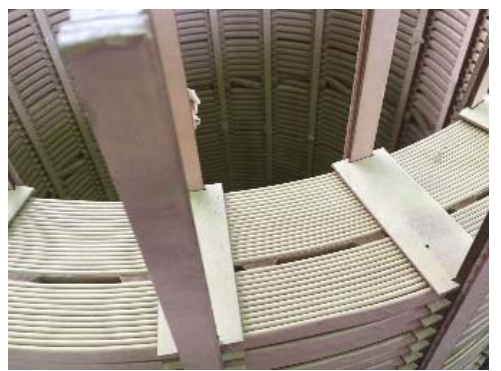

(a)

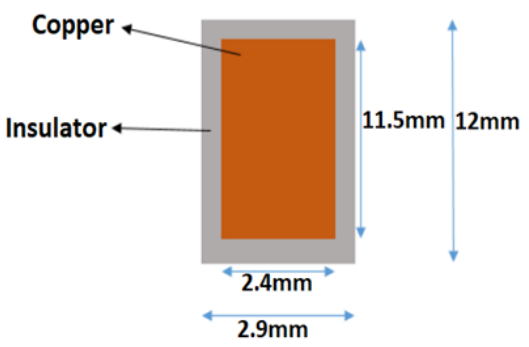

(b)

Figure 9. (a) the transformer winding stricture with $5 \mathrm{~mm}$ of air gap between particular turns (b) the conductor measurement dimensions

As given in Table 1 the winding dimensions such as inner and outer radius were calculated. The total circumference of the conductor is given by $2 \pi r$. Based on winding parameters provided in Table 1, capacitance, resistance and inductances are calculated.

Table 1. The Transformer Parameters Specifications

\begin{tabular}{lc}
\hline \multicolumn{2}{c}{ Winding Geometry in mm } \\
\hline Conductor width $(W)$ & 2.4 \\
Conductor high $(h)$ & 11.5 \\
Insulation thickness $t_{p}$ & 0.5 \\
Number of turns per disc $(m t)$ & 30 \\
Air gap insulation thickness & 5 \\
Pressboard thickness between discs $d$ & 3 \\
Winding inner radius $r$ & 374.5 \\
Outer diameter $d o$ & 933 \\
Inner diameter $d i$ & 749 \\
The total circumference of the conductor $C_{i r}$ & 94238.64 \\
\hline
\end{tabular}

\subsection{Comparison between the Measurement and Simulation}

The model is applied to simulate the frequency response of the continuous disc winding. Figure 10 shows the measured and the simulated responses of the HV winding. The dashed line presents the measured 
response while the solid line is the simulated response. The two responses show the same path of negative and positive slope. Nonetheless, there are some differences in the resonance at the high-frequency region. These resonances are not shown in the calculated response. it is believed that this is because $5 \mathrm{~mm}$ air gap only included in series capacitance and self inductance calculation. However, it is required to included in mutual inductance calculation. The same transformer is recommended to be studied in the future and calculate the mutual inductance with the air gap effect.

However, Figure 11 shows the measured and simulated responses of the same winding after improvement. The simulated response shows more similar to the measured response. This is because of some changes in the winding resistance $R_{s}$, conductance, $G_{s}$, and self-inductance. This improvement is implemented using trial and error method. The changes are applied by decreasing winding resistance, conductance, and self-inductance. The total results of the transformer winding electrical parameters are provided in Table 2. It also includes parameters of the improved simulated response. To further understand the results shown in Table 2, more investigation is needed on the chosen transformer winding structure and the calculation of its electrical parameters. This future recommendation is to explain the reason of minor different between simulation and measured responses. Even though, the assumed spacing are air gap. But in actual transformer it includes press board and oil partials which is believed makes the differences in simulated and measured responses.

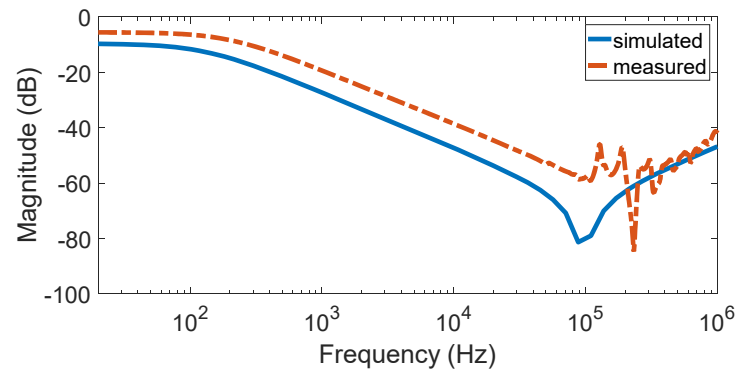

Figure 10. The calculated vs. measured responses for the HV winding of 96 discs winding

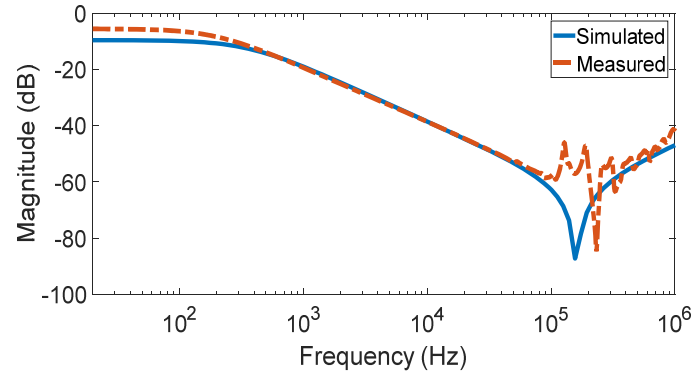

(a)

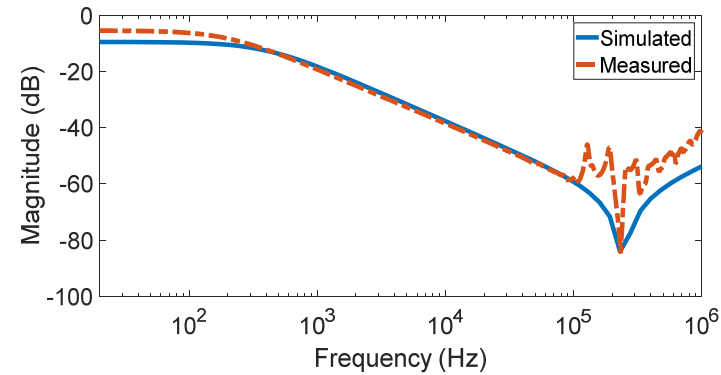

(b)

Figure 11. The Adjusted calculated vs. measured response (a) presents first improved results (b) presents the second improved results

Table 2:The Total Results of the Transformer Model Electrical Parameters Calculation

\begin{tabular}{|c|c|c|c|}
\hline \multirow{3}{*}{ Parameters } & \multirow{3}{*}{ Calculated response } & Response & Response \\
\hline & & in & in \\
\hline & & Figure 11(a) & Figure $11(\mathrm{~b})$ \\
\hline$C t$ & $3.18 \times 10^{-11} \mathrm{~F}$ & - & - \\
\hline $\mathrm{Cd}$ & $2.79 \times 10^{-9} \mathrm{~F}$ & - & - \\
\hline$C \operatorname{sh} v$ & $2.82 \times 10^{-9} \mathrm{~F}$ & - & - \\
\hline Gshv & $3.55 \times 10^{-9} \Omega$ & $3.55 \times 10^{-12} \Omega$ & - \\
\hline$R s h v$ & $0.8806 \Omega$ & $0.88 \times 10^{-9} \Omega$ & $1 \times 10^{-3} \Omega$ \\
\hline$M R$ & Matrix $96 \times 96$ & - & - \\
\hline$M L$ & Matrix $96 \times 96$ & $\mathrm{ML} / 100$ & $\mathrm{ML} / 3$ \\
\hline $\mathrm{Cg}$ & $0 \mathrm{~F}$ & - & - \\
\hline
\end{tabular}

Indonesian J Elec Eng \& Comp Sci, Vol. 14, No. 1, April 2019 : 219 - 229 


\subsection{RLC Analysis}

Based on the obtained results, it can be realized that the frequency response is affected by the change of winding $R, L$ and $C$ values. The changes in electrical parameters cause the frequency response to shift towards lower or higher frequency. To investigate the sensitivity of the model and simulate winding faults, the following changes are applied:

a) Increase of series capacitance $C_{s}$ as shown in Figure 12.

b) Increase of series resistance $R_{s}$ as shown in Figure 13.

c) Increase of self-inductance $L_{s}$ as shown in Figure 14 .

By increasing the winding capacitance, the response is shifted towards low frequency. The simulated response in Figure 12 represent the winding when it has high capacitance which is ten times higher than the normal winding response. By referring to Table 3 which is taken from other literature, the increase of series capacitance is mainly due to the aging of transformer insulation. Table 3 shows the investigated parameters that influence the frequency response.

On the other hand, the increase of series resistance is affecting the response at low frequency as shown in Figure 13. In the figure, the simulated response at frequencies below $10 \mathrm{kHz}$ showed a drop in magnitude. The increase of resistance is usually due to damages such as in the tap changer according to Table 3. Based on a study on tap changer damage in [15], findings in the reference also shows a similar effect on the measured response which refers to a coking in the tap changer.

The increase of self-inductance by ten times of the original value has a significant change in the simulated response. The anti-resonance which was originally at $200 \mathrm{kHz}$ has been shifted towards low frequency at $30 \mathrm{kHz}$ and showed a drop in magnitude on the negative slope. Such changes on the response is believed to be due to short circuit and core deformation as mentioned in Table 3 .

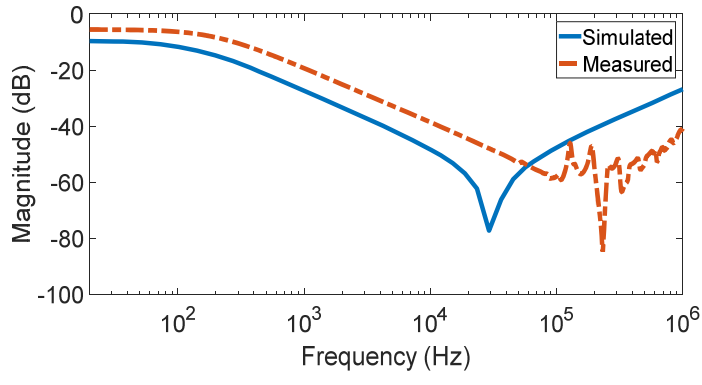

Figure 12. Increasing of series capacitance by 10 times $(\mathrm{Cshv} \times 10)$

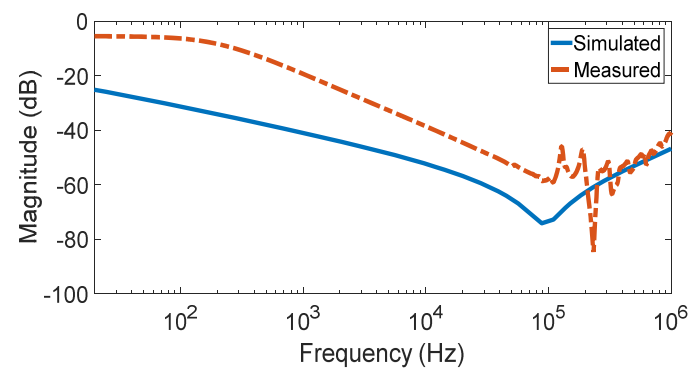

Figure 13. Increasing the series resistance by $10^{3}$

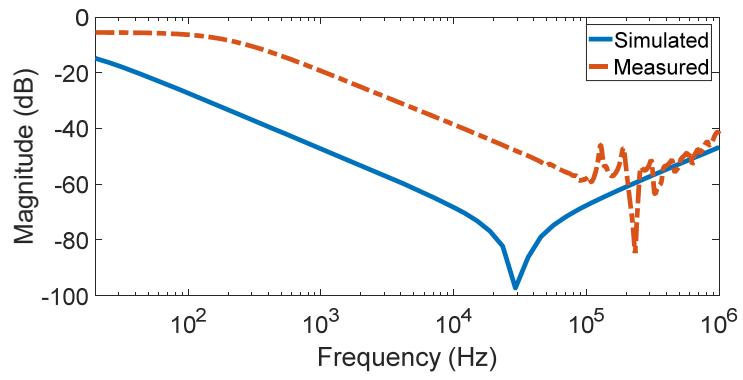

Figure 14. The changes in self-inductance which increased 10 times $(\mathrm{ML} \times 10)$

Table 3. Model Parameters and the Transformer Faults Which Influence [16]

\begin{tabular}{ll}
\hline \multicolumn{1}{c}{ Model parameter } & \multicolumn{1}{c}{ Type of fault } \\
\hline Series capacitance, $C s$ & $\begin{array}{l}\text { Aging of insulation, } \\
\text { moisture content ingress and disk movement (displacement) }\end{array}$ \\
Resistance, $R s$ & $\begin{array}{l}\text { Short or broken disk, failure of caulking contacts, } \\
\text { tap changer damage. } \\
\text { Disk deformation, local breakdown, core deformation } \\
\text { winding short circuit. }\end{array}$ \\
\hline
\end{tabular}

Frequency response of transformer winding to investigate the influence of RLC (S.Al-Ameri) 


\section{CONCLUSION}

It has been noted that FRA is a reliable method to investigate the mechanical condition of transformer winding. This paper presents a study on a unique transformer winding structure to simulate the frequency response. This winding has $5 \mathrm{~mm}$ air gap in between winding turns 2 and 3 thus present a challenge to simulate the response as the winding turns are not uniformly distributed. In this study, we present a new technique which is to calculate the capacitance in between turns $C t$ separately. Similarly goes with the calculation of capacitance between discs, $C d$. In addition, the self-inductance per disc considered in this study is that there are actually two different self-inductances which are connected in series. This is due to the insulation gap in between turns 2 and 3. It has been observed that increasing the series capacitance causes shifting in the response towards low frequencies. Whilst increasing the winding resistance shows a drop in magnitude at the low-frequency region. In fact, the change in self-inductance shows a major effect on the response. The response shows a drop in the anti-resonance of the response. In the meantime, the drop in response is clearly shown at low frequencies. In this paper, RLC analysis only investigate the increasing of series capacitance, series resistance, and self-inductance. This is because we believed that these three parameters have major effect on the frequency response. Further study is recommended to develop state space model for this particular transformer which could be compare with the proposed model. This is to conclude which approaches can give similar to the measured response. But, it is believed that the minor changes between simulation and measured responses is because of the assumptions of the winding spaces. The spaces includes a wooden press board and oil partials which has an effect on the frequency response.

\section{SYMBOLS}

Nd Number of discs

$m t \quad$ Number of turns per disc

$d \quad$ The distance between two discs

$h \quad$ Height of the turns without insulation.

$w \quad$ Width of the turns without the insulation.

$C_{i r} \quad$ The total circumference of the conductor.

$\varepsilon_{o} \quad$ The permittivity of free space

$\varepsilon_{r} \quad$ Relative permittivity of the insulation paper

$C t$ The capacitance in between turns

Cd Capacitance in between the discs

\section{ACKNOWLEDGEMENTS}

This work is supported financially by the University Tun Hussein Onn Malaysia under Special Contract Grant vot U425 and GPPS PhD student grant project vot U708. This project also supported by Research Fund, RMC, UTHM"

\section{REFERENCES}

[1] N. Abeywickrama, Y. V. Serdyuk, and S. M. Gubanski, "High-frequency modeling of power transformers for use in frequency response analysis (FRA)," IEEE Trans. Power Deliv., vol. 23, no. 4, pp. 2042-2049, 2008.

[2] T. Committee, I. Power, and E. Society, IEEE Guide for the Application and Interpretation of Frequency Response Analysis for Oil-Immersed Transformers IEEE Power and Energy Society, no. March. 2013.

[3] Cigre WG A2.26, "Mechanical Condition Assessment of Transformer Windings Using Frequency Response Analysis (Fra)," Cigre, no. April, pp. 30-34, 2008.

[4] O. Särneroth, "Insulation Materials," library.e.abb.com, vol. 2, pp. 1-21, 2014.

[5] S. G. Sahoo, Saroja Kanti, "Winding Deformation Analysis in Power Transformers using Finite Element Method," pp. 341-346, 2014.

[6] Z. W. Zhang, W. H. Tang, T. Y. Ji, and Q. H. Wu, "Finite-element modeling for analysis of radial deformations within transformer windings," IEEE Trans. Power Deliv., vol. 29, no. 5, pp. 2297-2305, 2014.

[7] O. de Weck and I. Y. Kim, "Finite Element Method," Eng. Des. Rapid Prototyp., vol. 810, p. 26, 2004.

[8] A. Abu-Siada, "High Frequency Transformer Modelling using State Space Representation for FRA studies," 11th Int. Symp. Diagnostics Electr. Mach. Power Electron. Drives, 2017.

[9] M. F. M. Yousof, C. Ekanayake, T. K. Saha, and H. Ma, "A study on suitability of different transformer winding models for frequency response analysis," IEEE Power Energy Soc. Gen. Meet., pp. 1-8, 2012.

[10] E. Bjerkan, High Frequency Modeling Of Power Transformers, no. 195. 2012.

[11] B. J. Van Jaarsveld, "Wide band modelling of an air-core power transformer winding," no. December, 2013.

[12] D. B. Kandić, B. D. Reljin, and I. S. Reljin, "On modelling of two-wire transmission lines with uniform passive ladders," Math. Probl. Eng., vol. 2012, 2012.

Indonesian J Elec Eng \& Comp Sci, Vol. 14, No. 1, April 2019 : 219 - 229 
[13] Charles Q. Su, Electromagnetic Transients in Transformer and Rotating Machine Windings. Australia, 2012.

[14] S.V.Kulkarni S.A.Khaparde, Transformer Engineering: Design and practice. Bombay, 2004.

[15] S. Al-Ameri, M. F. M. Yousof, H. Ahmad, M. Alsubari, and M. A. Talib, "Examining Faulty Transformer Tap Changer using Frequency Response Analysis,” 2017 Int. Symp. Electr. Insul. Mater., pp. 259-262, 2017.

[16] A. Abu-Siada, N. Hashemnia, S. Islam, and M. Masoum, "Understanding power transformer frequency response analysis signatures," IEEE Electr. Insul. Mag., vol. 29, no. 3, pp. 48-56, 2013.

\section{BIOGRAPHIES OF AUTHORS}

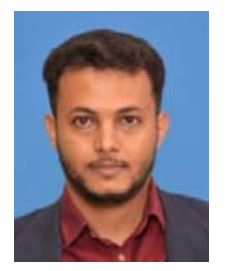

Salem Mgammal Awadh Nasser Al-Ameri received B.Eng. in Mechatronics Engineering from Asia Pacific University (APU) in 2012. He received M.Eng. in Electrical Power from Universiti Tun Hussein Onn Malaysia (UTHM) from 2014 to 2016. Currently he is pursuing Ph.D. Degree in Universiti Tun Hussein Onn Malaysia. His research is on transformer condition monitoring using FRA.

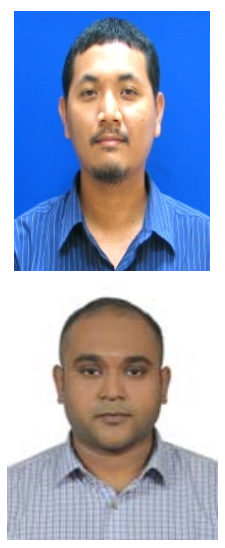

Mohd Fairouz Mohd Yousof received B.Eng. (Electrical) and M.Eng. (Electrical) both from Universiti Teknologi Malaysia (UTM) in 2008 and 2010, respectively. He is a lecturer at the Department of Electrical Power Engineering at Universiti Tun Hussein Onn Malaysia since 2009. He received Ph.D. degree from The University of Queensland, Australia in 2015. Currently he is on industrial attachment with Tenaga Nasional Berhad Research involving many research projects especially on condition monitoring of transformer.

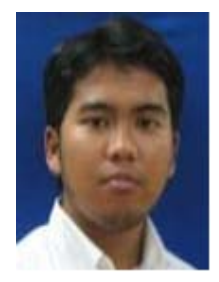

Avinash Srikanta Murthy received B.Eng. in Electrical and Electronics Engineering from Malnad College of Engineering in 2011. He received M.Tech. in Power and Energy Systems from National Institute of Technology Karnataka, Surathkal in 2013. He was working in Rural Electrification Corporation under Ministry of Power, India as an Lead Electrical Engineer from 2013 to 2014. Currently he is pursuing Ph.D. Degree at Centre of Electromagnetics and Lightning Protection Research (CELP) under Universiti Putra Malaysia. His research is on transformer deformation analysis using Frequency Response Analysis.

Norhafiz Azis received the B. Eng. degree in Electrical and Electronic Engineering (2007) from Universiti Putra Malaysia and PhD degree in Electrical Power Engineering (2012) from. The University of Manchester in UK. Currently he is a Senior Lecturer at the Department of Electrical and Electronic Engineering, Universiti Putra Malaysia, Malaysia. His research interests are in-service ageing of transformer insulation, condition monitoring, asset management and alternative insulation materials for transformers

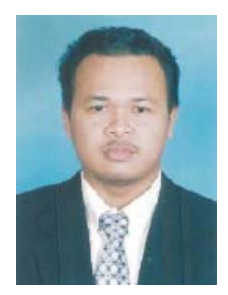

Mohd Aizam Talib received his Bachelor in Electrical Engineering from the University of Portsmouth, UK in 1997, and Master degree in Electrical Engineering from Universiti Tenaga Nasional (UNITEN), Malaysia in 2001. Upon graduation in 1997, he worked with ABB Transmission and Distribution Sdn Bhd as a Design Engineer. Since 1998, he has been employed by TNB Research Sdn Bhd as a Research Engineer. His research interests are in transformer condition monitoring, insulation diagnostic and dielectric measurements. He is currently a Ph.D. degree student at Universiti Teknologi Malaysia

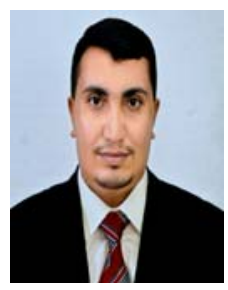

Ali Ahmed Ali Salem (Ali. A. Salem) was born in Sana'a, Yemen on March 1,1985. He received M.Eng. in Electrical Power Engineering from Universiti Tun Hussein Onn Malaysia (UTHM) from 2014 to 2016. Currently he is Pursuing Ph.D. degree at High Voltage in Faculty of Electrical Engineering, UTHM. His research interest includes the dynamic arc modelling of pollution flashover on high voltage outdoor insulators. 